\title{
An extremely rare case of adrenocortical cancer with cannon ball pulmonary metastasis
}

\author{
Vito Antonio Falcone, Ilaria Nardi, Maria Mesto, Vanessa Trotta, Vito Picca \\ Department of Intensive Respiratory Care Unit, San Paolo Hospital of Bari, Italy
}

\begin{abstract}
Multiple pulmonary nodules on chest X-ray, known commonly as cannon ball secondaries, are the classical presentation of hematogenous dissemination of a malignant tumor to the lungs. This almost always indicates an advanced stage of the disease with a very grim outlook in terms of cure or survival. In this case report, we present a patient with very extensive cannon ball lung metastases due to adrenocortical carcinoma with a more favorable prognosis. This is the first case described in the literature of cannonball lung metastases from adrenocortical tumor in a man.
\end{abstract}

\section{Introduction}

It is largely described that an adrenocortical cancer, a rare disease also called cancer of the adrenal cortex, can be responsible for pulmonary metastases [1-2]. In addition, cannon ball pul-

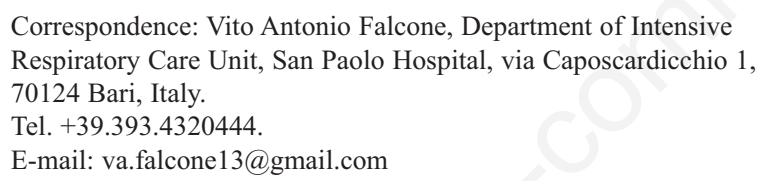

E-mail:va.falcone13@gmail.com

Key words: Cannon ball metastases; lung metastasis; malignancy; adrenocortical carcinoma.

Contributions: IN, MM, VT, data collecting and analyzing; VAF, manuscript drafting; VP, VAF, manuscript reviewing and literature search. All authors gave substantial intellectual contribution to the study, read and approved the final version to be published.

Conflict of interest: the authors declare no potential conflict of interests.

Informed consent: obtained.

Received for publication: 31 March 2019.

Accepted for publication: 12 September 2019.

${ }^{\circledR}$ Copyright: the Author(s), 2019

Licensee PAGEPress, Italy

Monaldi Archives for Chest Disease 2019; 89:1076

doi: 10.4081/monaldi.2019.1076

This article is distributed under the terms of the Creative Commons Attribution Noncommercial License (by-nc 4.0) which permits any noncommercial use, distribution, and reproduction in any medium, provided the original author(s) and source are credited. monary metastases have been associated with a wide spectrum of neoplasms [3]. However, this is the first case described in the literature of cannonball lung metastases caused by an adrenocortical tumor in a man.

\section{Case Report}

A 70-year-old man, no-smoker and no-diabetic, was taken to the Emergency Unit of the San Paolo Hospital in Bari, Italy, on August 21, 2017. His medical history reported a right adrenocortical carcinoma, surgically removed in 2002; in February and April 2011, respectively, the patient had been subjected to the atypical resection of the upper lobe of the left lung and to the complete resection of the lower lobe of the right lung. In both cases the histological diagnosis of pulmonary biopsies had concluded for secondary locations of adrenal carcinoma. No metastatic lesions were found till 2013, when the patient decided to interrupt any radiological control and any treatment but palliation.

In the last 5 days, he had developed cough, hemoptysis, progressive wheezing without fever. A hypertensive crisis was detected in the emergency room. Routine blood tests revealed normal white and red blood cells, hemoglobin $14.9 \mathrm{~g} / \mathrm{dL}$ (1317.5), PCR 12,1 mg/L (0-5), NT-PROBNP 3081 pg/ml (0-125). The physical examination revealed a respiratory rate of $30 / \mathrm{min}$ and the use of accessory muscles of respiration, heart rate $120 / \mathrm{min}$, blood pressure $160 / 90 \mathrm{mmHg}$, oxygen saturation $80 \%$ in the ambient air, swelling of the foot for edema. Chest examination revealed a reduction of breathing sounds in all-field and diffuse bilateral cracklings and acute on chronic global respiratory failure thanks to a blood gas analysis performed in the ambient air and a spontaneous breathing. Viral serology for hepatitis (A, B, C), respiratory syncytial virus, Epstein Barr virus, Cytomegalovirus were negative. The serum Mycoplasma and Chlamydia Pneumoniae antibodies IgM-A-G were also negative. A routine chest X-ray - posteroanterior and lateral views showed multiple large lung masses in both fields, of which the biggest measured $11 \mathrm{~cm}$, which were highly suggestive of secondaries (Figure 1). A CT scan of the chest revealed more bilateral "cannon ball" pulmonary metastases (Figure 2). At that moment only, the family of the patient gave us the images of a CT scan of the chest taken in February 2017, which confirmed the presence of many lung masses which had increased of over 2 $\mathrm{cm}$ each one during the last months (Figure 3). A fiberoptic bronchoscopy showed no stenosis of bronchi, nor any endobronchial lesion. The patient died due to respiratory failure after 3 days, despite an initial clinical improvement obtained through medical cares and oxygen therapy. 


\section{Discussion}

In this case, medical history, CT scan abnormalities, biochemical parameters were suggestive of cannonball pulmonary metastases from adrenocortical cancer. In addition, the histological specimens confirmed the diagnosis.

The adrenocortical carcinoma is an aggressive cancer originating in the cortex of the adrenal gland. It is a rare tumor, with an incidence of 1-2 per million population/year. At the time of diagnosis, it has often invaded nearby tissues or metastasized to distant organs, and the overall 5-year survival rate is only $20-35 \%$ [4-7]. The lung is an uncommon site for metastasis from adrenal gland cancer.

On CT, cannon ball metastases refer to large, well circumscribed, round pulmonary masses that appear like cannon balls [2]. In this regard, it should be noted that these lesions may be mimicked by a broad range of clinical entities, including septic embolism, tuberculosis, angioinvasive aspergillosis, rheumatoid nodules, and others [8]. However, confusion between these conditions is rare due to differences in clinical presentation, and biochemical parameters, such as in the present case.

Multiple pulmonary metastases from adrenal gland cancer have been extensively described [9-10]. On the other hand, cannon ball pulmonary metastases have been classically associated to urogenital tract malignancies (renal cell carcinoma and choriocarcinoma), gastrointestinal tumors and sarcomas [11]. In this regard, to the best of our knowledge, this is the first case in the literature of cannon ball pulmonary metastases from adrenocortical cancer in a man.

In literature, a similar case in a woman has been reported in 2012 [12]; typically, these kind of lesions are more frequent in women, especially if they are associated with endocrine syndromes. In addition, it is important to remark that cannon ball metastases usually indicate advanced disease and portend poor prognosis [13]; on the contrary, in this case, six years had passed since the diagnosis of pulmonary metastases to patient exitus.

\section{Conclusions}

In presence of adrenocortical tumor, it is reasonable to suspect the occurrence of cannon ball lung metastases when CT findings are suggestive of it. Although these kinds of lesions are generally related to more aggressive histotypes of cancer such as renal cell carcinoma or choriocarcinoma, this case raises the possibility of cannonball lung metastases also from a less aggressive tumor with a better outcome.

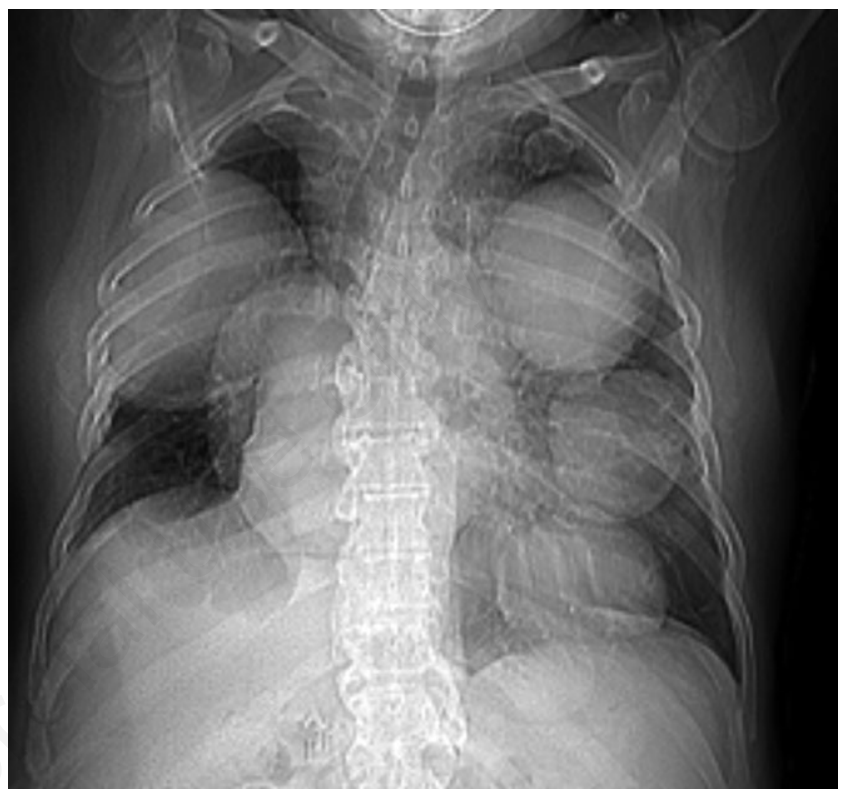

Figure 1. Chest X-ray anterior posterior view (August 2017).

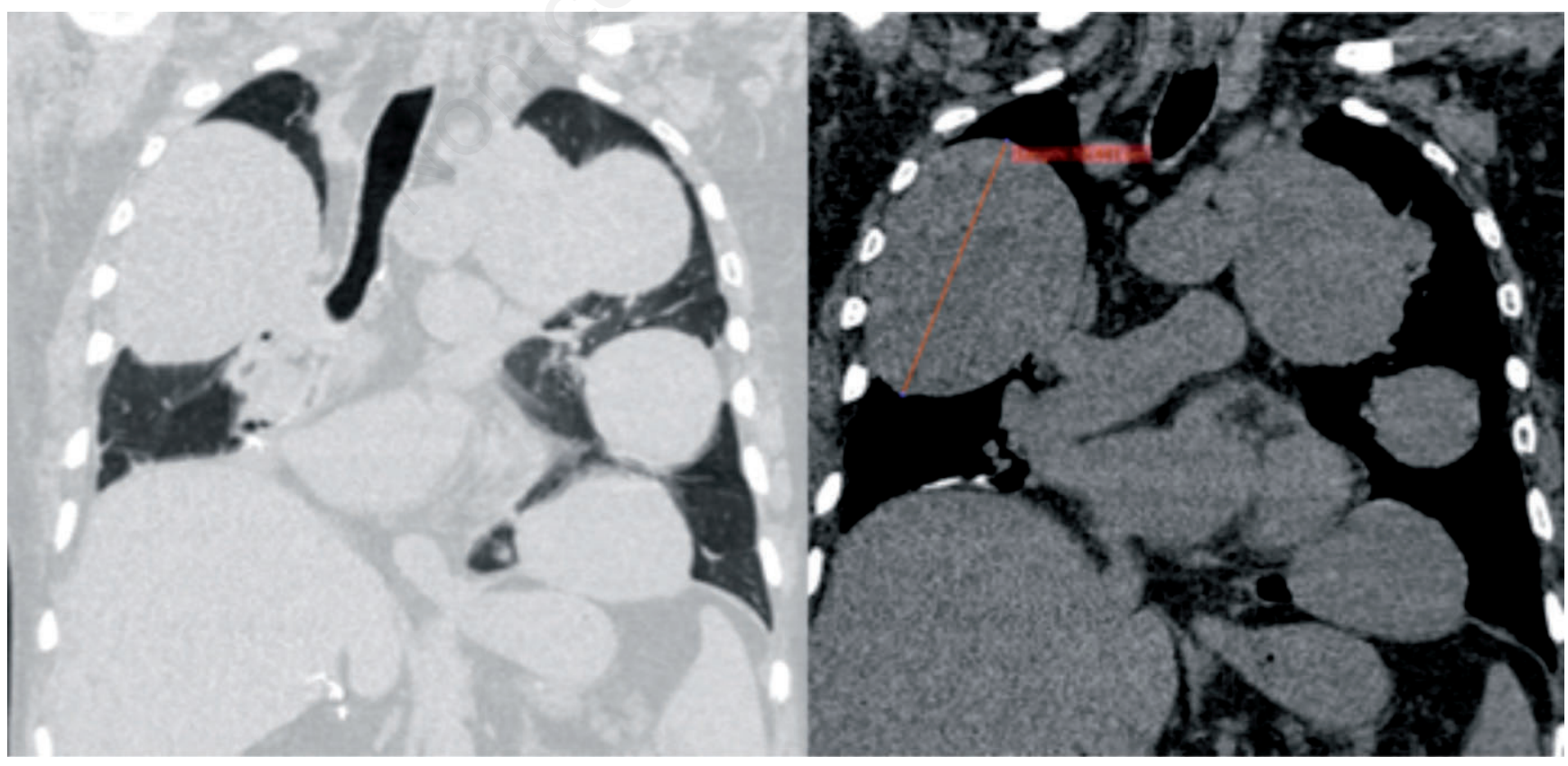

Figure 2. Coronal CT scan images of the chest (August 2017). 


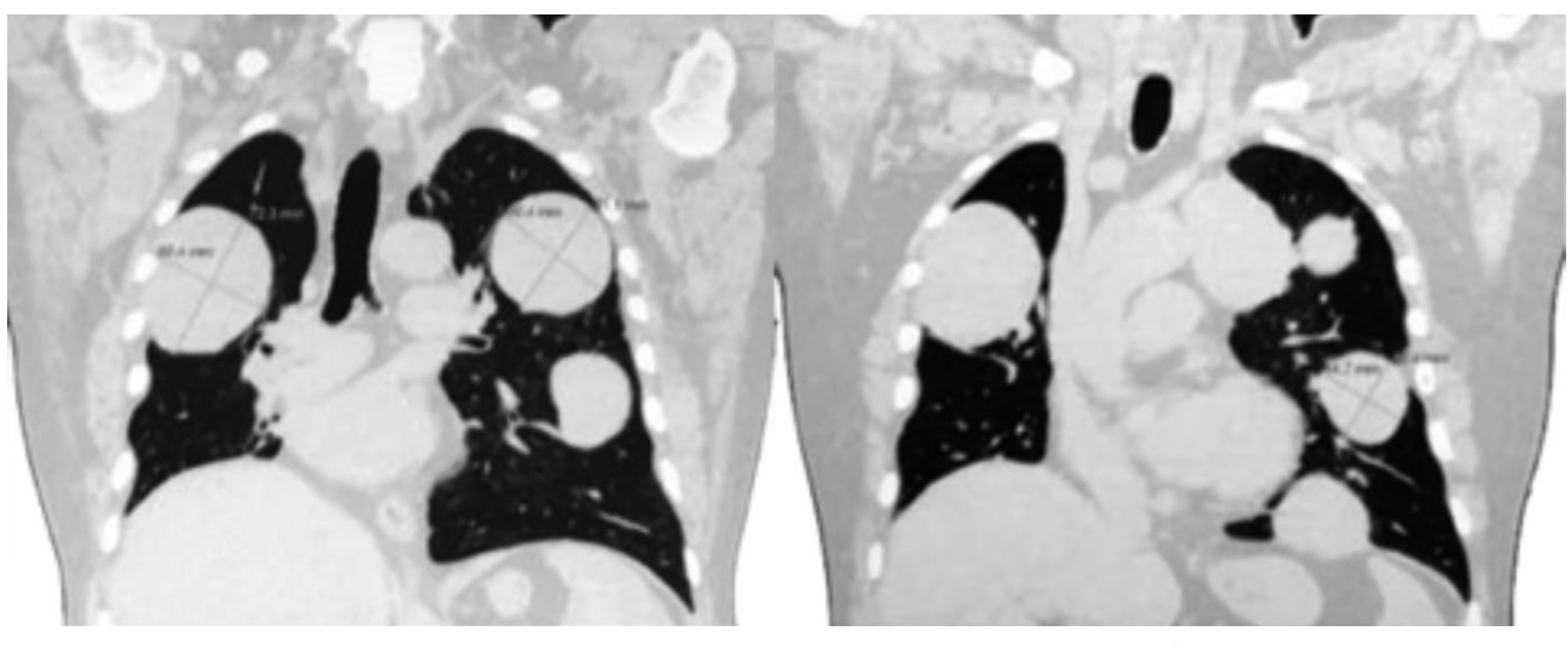

Figure 3. Coronal CT scan image of the chest (February 2017).

\section{References}

1. Ammannagari N, Polu V. 'Cannon ball' pulmonary metastases. BMJ Case Rep 2013;2013:bcr2012008158. doi:10.1136/bcr2012-008158.

2. Bickle I. Cannonball metastases (lungs). [Internet] Radiopaedia.org. Available from: https://radiopaedia.org/articles/cannonball-metastases-lungs?lang $=\mathrm{gb}$

3. Kshatriya R, Patel V, Chaudhari S, et al. Cannon ball appearance on radiology in a middle-aged diabetic female. Lung India 2016;33:562-8.

4. Arkless R. Renal carcinoma: how it metastasizes. Radiology 1996;84:496-501.

5. PDQ Adult Treatment Editorial Board. Adrenocortical Carcinoma Treatment (PDQ $\left.{ }^{\circledR}\right)$. [Internet]. Available from: https://www.ncbi.nlm.nih.gov/pubmedhealth/PMH0032533/

6. Brunt LM, Moley JF. Adrenal incidentaloma. World J Surg 2001;25:905-13.
7. DeVita VT, Hellman S, Rosenberg SA. Cancer: principles \& practice of oncology. Philadelphia: Lippincott-Raven; 2005.

8. Buchholz S, Szawarski P, Dawson SL. An odd case of multiple "cannonball metastasis" Postgraduate Med J 2003;79:542-3.

9. Allard P, Yankaskas BC, Fletcher RH, et al. Sensitivity and specificity of computed tomography for the detection of adrenal metastatic lesions among 91 autopsied lung cancer patients. Cancer 1990;66:457-62.

10. Karanikiotis C, Tentes AA, Markakidis S, et al. Large bilateral adrenal metastases in non-small cell lung cancer. World J Surg Oncol 2004;2:37.

11. Agarwal R, Mukhopadhyay J, Lahiri D, et al. Cannon-ball pulmonary metastases as a presenting feature of stomach cancer. Lung India 2015;32:300-2.

12. Khan M, Banerjee R. A case of adrenocortical cancer with cannon ball pulmonary metastasis and primary hyperaldosteronism. Endocrine Abstracts 2012;28:P154.

13. Flavin R, Finn S, McErlean A, et al. Cannonball metastases with favourable prognosis. Ir J Med Sci 2005;174:61-4. 
